\title{
Consumer Confusion and Green Consumption Intentions from the Perspective of Food-Related Lifestyles on Organic Infant Milk Formulas
}

\author{
Shao-Ping Yang ${ }^{1}$, Shu-Chun Chang ${ }^{1, * \mathbb{D}}$, Ta-Ching Liang ${ }^{2}$, Rospita Odorlina P. Situmorang ${ }^{3}$ (D) \\ and Minhas Hussain ${ }^{3}$ \\ 1 Graduate Institute of Bio-industry Management, National Chung Hsing University, \\ Taichung City 402, Taiwan; sirius1993@gmail.com \\ 2 Department of Leisure \& Recreation, National Formosa University, Huwei Township 632, Taiwan; \\ taching@nfu.edu.tw \\ 3 Department of Forestry, National Chung Hsing University, Taichung City 402, Taiwan; \\ pita_80s@yahoo.com (R.O.P.S.); minhasmunna4@gmail.com (M.H.) \\ * Correspondence: kimichang@dragon.nchu.edu.tw; Tel.: +886-422-840-491 (ext. 21)
}

check for updates

Citation: Yang, S.-P.; Chang, S.-C.; Liang, T.-C.; Situmorang, R.O.P.; Hussain, M. Consumer Confusion and Green Consumption Intentions from the Perspective of Food-Related Lifestyles on Organic Infant Milk Formulas. Sustainability 2021, 13, 1606. https://doi.org/10.3390/ su13041606

Received: 23 December 2020

Accepted: 22 January 2021

Published: 3 February 2021

Publisher's Note: MDPI stays neutral with regard to jurisdictional claims in published maps and institutional affiliations.

Copyright: (c) 2021 by the authors. Licensee MDPI, Basel, Switzerland. This article is an open access article distributed under the terms and conditions of the Creative Commons Attribution (CC BY) license (https:// creativecommons.org/licenses/by/ $4.0 /)$.

\begin{abstract}
A sustainable lifestyle and green consumption are becoming popular nowadays due to increased awareness of environmental issues and many incidents regarding food safety. This has triggered the rapid development of the marketing of green products and the promotion of many green brands which causes confusion among consumers. This paper's purpose is to evaluate the relationship between this consumer confusion and different Food-Related Lifestyles (FRLs) tending towards green consumption, taking as a case study organic infant milk formula. This study was based on an online survey which was conducted with 381 Taiwanese parents and carried out from January to February 2019. Through cluster analysis, this study categorized the different FRLs into three groups, i.e., consumers unfamiliar with food product quality, consumers who value food quality, and consumers who value food practicality. This study found that there is no significant correlation between different levels of consumer confusion and different FRLs. Furthermore, different consumers' FRLs have significant correlations with green consumption intention. This study also found a positive relationship between consumer confusion and green consumption intention.
\end{abstract}

Keywords: organic infant formulas; food-related lifestyles; consumer confusion; green consumption

\section{Introduction}

In recent years, rising environmental awareness has prompted governments, corporations, and the public to pursue goals of energy conservation, pollution reduction, resource protection, and sustainable development. The promotion of sustainable lifestyles such as green consumption has also attracted a major growth in environmentally friendly products. Green consumption refers to the purchasing of green products to mitigate environmental impacts when consumption is inevitable [1]. However, "green products" is a generalized term, whereas some products are situated in a grey area, difficult to define as green products, and others meet every criterion for being a green product, e.g., organic products or organic foods. The Commission of the European Communities [2] defined green products as those that have lower impacts on and risks to the environment, prevented waste, and used less resources in manufacturing. In other words, green products are pollution-free products that are reusable or preservable [3]. By this definition, organic food refers to food produced in accordance with ecological principles both in the processing and materials used (zero chemicals and reduction of all types of pollutants, using renewable energy sources, and safeguarding genetic diversity) [4,5] and these are categorized as green products. 
The increase in green consumption has also been triggered by several food safety incidents that have happened in many locations or countries. A viral incident regarding food safety that raised high concerns in the public was the melamine-contamination of infant milk formulas in 2008 in China. This incident also affected Taiwan because the milk formula producers used to import raw materials from China [6]. Moreover, China and Taiwan are neighboring countries with mutual influence. This tragedy has gradually changed the mindset of Taiwanese consumers causing them to shift towards green consumption, including that of organic milk formula products. Regarding green consumption, especially for organic foods, the Council of Agriculture (COA) reports that the consumption of organic foods in Taiwan is increasing year by year which is indicated by the increase in organic agricultural productions by about $27.7 \%$ per year between 2008 and 2019 [7]. The Taiwan Organic Trade Association has also reported that parents' concern over infant nutritional intake is increasing, which is boosting the popularity of organic infant food products among parents. This parental concern was taken as an opportunity by producers and distributors to earn more income by producing and promoting new brands of organic formula for infants.

In Taiwan, organic infant milk formulas are not produced locally. However, various brands of organic milk formulas distributed in Taiwan are imported from other countries. These organic infant milk products are certified by the producers' countries in ways not familiar to Taiwanese consumers. If these distributors do not offer various brands of infant milk formula separately with clear distinctions between them, consumers will be confronted with a number of similar products. This might create difficulties and increase confusion for consumers in distinguishing and making a choice between products [8]. Additionally, a number of organic formula milk brands offered by two or more manufacturers within the same distribution channel have similar cover designs. This is a major cause of confusion among consumers. Considering this problem, we were interested in studying the correlation between consumer confusion and purchase intention in relation to organic infant formulas. We also intend to evaluate the contribution of consumer food-related lifestyle aspects (FRLs) to consumer confusion and green consumption.

In the past, scholars and marketing professionals employed various theories and models to understand consumer behavior and lifestyle. In 1963, the concept of "consumer lifestyle" was introduced into the marketing field, and researchers have developed numerous relevant models and scales. Some of these are applicable to most scenarios and products, whereas others are designated for specific products or consumer groups. These models and scales have been employed by scholars according to what they wish to prove or disprove. As this study is based on organic infant formulas classified as a food product, we used the food-related lifestyles (FRLs) model developed by Brunsø and Grunert [9] to evaluate the correlation between lifestyles and consumer confusion. Relevant studies have previously discussed lifestyles, consumer confusion and green consumption separately, and until now, studies discussing the three above mentioned topics collectively have been limited. Therefore, by using the FRL-based approach to explore consumer confusion and green consumption intentions regarding organic infant formulas, this study has the objective to examine the correlation between: (1) different types of confusion and consumers' FRLs; (2) different types of consumers' FRLs and their green consumption intentions; and (3) consumer confusion and green consumption intention.

\section{Literature Review}

2.1. Green Consumption Intention

\subsubsection{Green Consumption}

The green consumption concept was first proposed in the Green Consumer Guide [10], where it is defined as consumers' choice to purchase environmentally friendly products in order to achieve physio-psychological health through sustainable consumption patterns. Although the environmental impacts of green products and environmental products cannot be completely eliminated, these terms are commonly used to describe products that are 
environmentally friendly [11]. Yu and Lai [1] proposed that green consumption is the action of purchasing green products to mitigate environmental impacts when consumption is inevitable. Speth [12] stated that green consumption does not represent the reduced consumption but rather consumers' expectations of corporations producing green products for consumption.

Green consumption enables consumers to express their environmental protection tendencies through consumption of green products and increasing their utilization efficiency [13]. In marketing, green consumption is defined as the production, promotion, and discounting prices of products and services on the basis of environmental protection [14]. Efficient methods of promotion of green consumption are through promotion of ecolabel programs of products and services, campaigns on public awareness, encouraging green production standards and certification, and green government procurement.

\subsubsection{Green Products}

Green products are pollution-free and reusable or preservable products [3]. Nimse et al. [15] indicated that the green products include the product recyclability, less packaging, used the minimum required material, and conservation of energy resources. Chen and Chai [16] proposed a similar definition stating that green products are produced with less packaging or materials of lesser toxicity to reduce their hazardous impact on the environment. Junior et al. [17] indicated that green products exhibit the same functions as due conventional products and have lesser environmental impacts throughout the product life cycle.

In the Green Consumption book [18], green products are divided into numerous categories, one of them is "green food". Green food refers to the food products that do not cause public harm or pollution to the environment. In that book, it also stated the term "organic foods" which is stricter on zero environmental impacts on production and raw materials; it is more beneficial to consumers' health and environment compared with green foods. By purchasing organic foods, consumers can achieve the goal of green consumption which leads to sustainable lifestyle.

\subsubsection{Sustainable Marketing}

Sustainable marketing is commonly defined as the process of creating, communicating, and delivering services to customers which concerns environmental and social aspects $[19,20]$. Sustainable marketing is based on the principles of resource sustainability along with social and environmental goals in business [21]. Nowadays, sustainability has become a mainstream issue, which shows that people are increasingly taking interest in issues related to sustainability. This depicts that sustainable marketing does not only focus on resource sustainability but also on raising awareness about the importance of sustainable consumption [22,23].

The increasing public awareness on the importance of sustainable consumption is a prerequisite condition in the development of sustainable marketing. The shifting towards green consumption such as inclination towards organic food as a new lifestyle has increased the organic food demand. However, some producers or suppliers sometimes take unfair benefit from the organic market, for example, by imitating names, labels, or providing unclear product's information which causes confusion among consumers. This situation can create an unfair market environment, erode consumer trust, and destroy sustainable marketing in the long run.

\subsection{Food-Related Lifestyles (FRLs)}

\subsubsection{Definition of Lifestyle}

Lazer [24] defined lifestyle as a systematic concept of living. In general, lifestyle refers to the unique way of living which the overall society or a specific smaller population adopt [25]. This definition has commonly been employed by subsequent studies on lifestyle-related green behavior [26-30]. Consumer lifestyle applications is a commonly discussed topic among researchers, including both consumer and market-oriented approaches. 
Plummer [25] stated that lifestyles are used for market segmentation, and it is also used to divide the overall consumer population into groups according to various characteristics. Todd, et al. [31] also proposed that lifestyles reflect the different styles of living and consumption patterns of consumers, and thus are beneficial for market segmentation. Nie and Zepeda [32] stated that rather than summarizing consumer behavior, lifestyles can contribute to segmentation of consumers and to understand the consumer attitude and motivation. Reynolds et al. [33] suggested that consumer lifestyle studies are employed to evaluate the concrete behavior of consumers, specifically the consumers' activities, affairs that they are most interested in, and opinions on each theme.

However, Brunsø et al. [34] proposed an opposing viewpoint related to lifestyle functions. They defined lifestyle as an intervention system of the knowledge structure that connects situation-specific product perceptions with abstract goals, thereby influencing individuals' personal values. The intervention system includes declarative knowledge (e.g., knowledge that describes the attributes and concepts of things and their relation to each other) and procedural knowledge (e.g., knowledge to perform an action or skill), which constitute bottom-up and top-down information-processing routes. This viewpoint on lifestyles vastly differs from the lifestyle definitions of the most relevant studies and shows that scholars have diversified definitions of lifestyle.

\subsubsection{FRL Model}

Brunsø and Grunert [9] developed the food-related lifestyle model (Figure 1) which can effectively evaluate various lifestyles of consumers who purchase food products, and it is applicable on transcultural situations. The model has five domains between the process of connecting product categories and concrete attributes to value, namely ways of shopping, quality aspects, cooking methods, consumption situations, and purchasing motives. Previous study conducted by Van Huy [28] modified the Brunsø and Grunert's FRL segmentation that includes innovativeness (novelty), attention to healthy food, love of cooking, and love of local and organic food. However, those contents are still related to one another. In this study, the FRL segmentation mostly followed the original concept of Brunsø and Grunert's study with a few changes on "cooking methods" termed to be "cooking attitude".

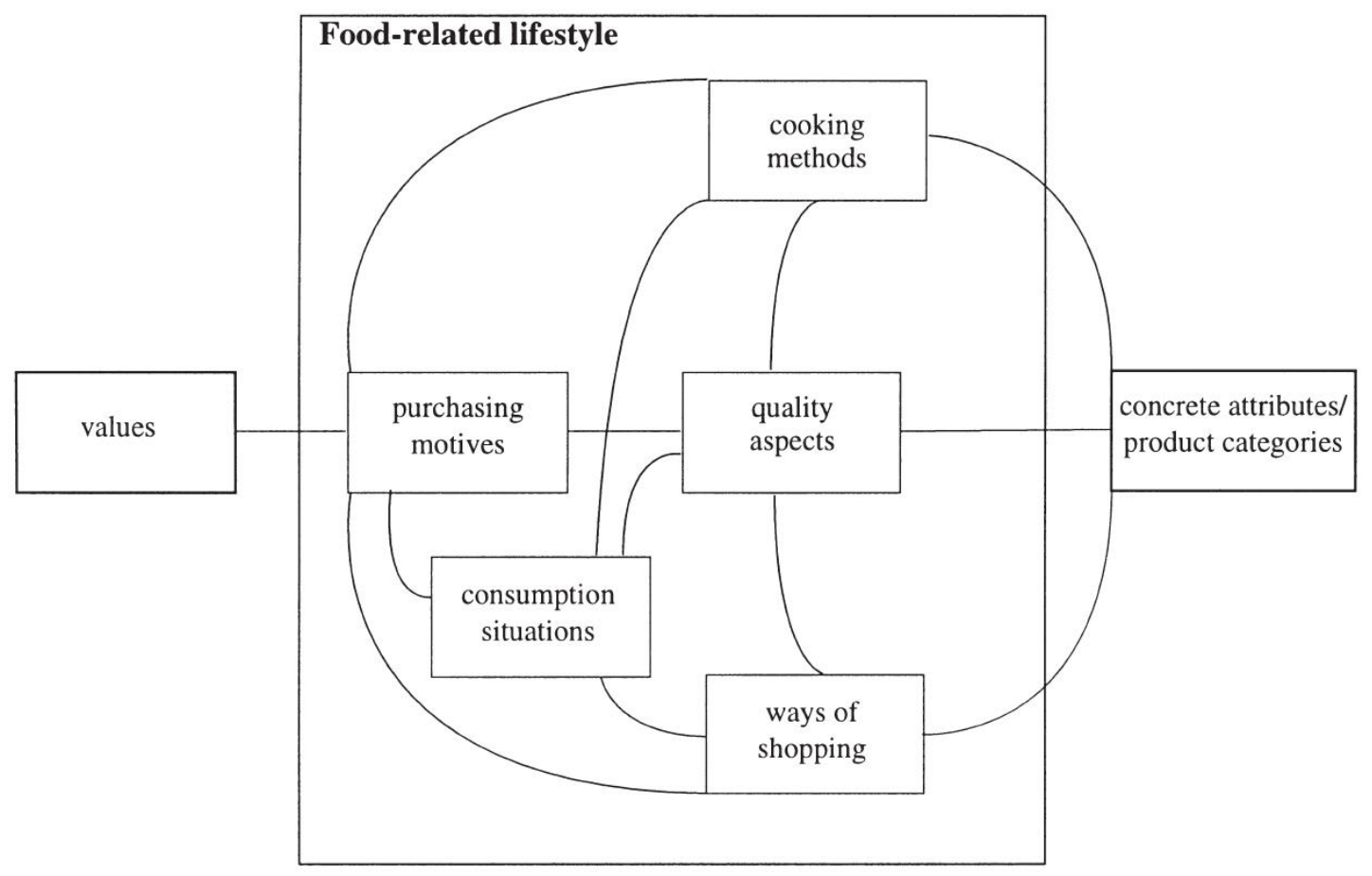

Figure 1. Food-Related Lifestyles (FRL) model (Source: Brunsø and Grunert [7]). 
O'Sullivan et al. [35] explained the five domains of FRLs as follow: (1) Ways of shopping: this refers to the consumer's purchase behavior toward food products, i.e., making impulsive purchases, making purchases after widespread consideration, being inclined to read food labels, being prone to act according to others' suggestions, having a preference for purchasing food at one-stop shopping or food stores, as well as whether the consumer uses shopping lists; (2) Quality aspects: this refers to the consumer's attitude toward product properties, including healthiness, nutrition, freshness, and luxury; (3) Cooking method: this refers to how the purchased products are cooked in meals, the amount of time spent to prepare, and the degree of preparation for each meal. This domain mainly inspects whether cooking is a social activity, a domestic labor activity participated in by all family members, or women's duty; (4) Consumption situations: this refers to how consumers arrange meals and snacks for each day and evaluates the importance of eating; (5) Purchase motives: this refers to the consumer's expectations towards meals and the importance of meals to the consumers. This domain includes the importance of the social, traditional, and safety impacts of certain products to the consumers.

\subsection{Consumer Confusion}

\subsubsection{Definition of Consumer Confusion}

The origin term of consumer confusion is "likelihood of confusion" which is applied in legal fields regarding copyright laws and litigation. To avoid misinterpretation, the term "consumer confusion" is used in this study because this study mainly explored consumer behavior, which it does not emphasize the legal aspect of consumer confusion aside from the legal definition of the term.

\section{Legal Aspect of Consumer Confusion}

The Taiwan government through the Ministry of Economic Affairs stipulated the Examination Guidelines on Likelihood of Confusion in 2004 and produced Likelihood of Confusion-Trademark Act. This regulation defines trademark confusion as, when a third party who is not the trademark owner uses the same trademark, thereby confusing consumers and causing them to misrecognize the actual trademark source. Hence, this act has functioned to protect consumers through recognizing the source of the trademarked products or services.

In the Likelihood of Confusion-Trademark Act, Lu [36] focused the term of confusion due to the similarities or identicalness of trademark or product series. Even though consumers are being aware of products' authenticity from different manufacturers, the similar trademark causes are misperceived as originating from a similar source. This also encompasses situations in which consumers have distinguished the product to originate from a different source yet misinterpret the source to be related to the source of the original product [37]. Lu [36] stated that when trademarks or trademarked products are greatly similar, consumers may be unable to differentiate products or services from different manufacturers, thereby it causes confusion and misrecognition.

\section{Consumer Confusion in Marketing}

From marketing aspect, consumer confusion is commonly discussed alongside imitation strategies. Shenkar [38] stated that imitation strategies can enhance corporation competitiveness and avoid risks faced by the first movers. By employing pre-existing marketing channels or regulation standards, corporations can modify the original product to meet consumer preferences, thereby greatly reducing their research and development costs. However, imitation strategies also introduce negative influences for corporations and consumers. Foxman et al. [39] stated that imitation strategies can cause consumers' dissatisfaction on a particular brand because of a wrong purchase from original product. However, consumers may also feel satisfied with the product and acknowledge that it is an imitation brand, thereby it develops a preference for an imitation brand. Another option is that the consumers also may first feel satisfy toward the purchased brand without 
being aware that it is an imitation brand, then they are becoming dissatisfy after realizing the imitation brand. Therefore, from a consumer viewpoint, the most direct influence of imitation strategies is consumer confusion which cause wrong purchases, applying products incorrectly, and misunderstand or misinterpret a product's properties [40]. The true information presenting in the products are crucial for consumers because they need it for decision-making process and making choices.

A processing ability is a decision-making factor for consumer confusion. Foxman et al. [39] stated that consumer confusion is the result of one or many errors in the inference process. Through distinguishing an unfamiliar brand using knowledge on brands that they are familiar with, consumers may develop an uncertainty towards the attributes or properties of the unfamiliar brand. Turnbull et al. [41] proposed a similar viewpoint that consumer confusion is defined as the inability of consumers to accurately describe products or services in the information absorption process, resulting in misunderstanding or misinterpretation of the market. From a marketing aspect, consumer confusion originates from corporation strategies and consumer psychology approaches. Regardless, corporations and consumers are interdependent and indivisible, and producers and consumers occasionally influence each other directly or indirectly on products. In this study, we adopted the consumer confusion definitions of Walsh and Mitchell [40] and Turnbull et al. [41] that is, consumer confusion is caused by consumers being unable to accurately assess the product attributes in the information absorption process, which causes the misinterpretation of markets and products.

Consumer confusions are divided into similarity confusion, overload confusion, and ambiguity confusion [42]. These segmentations have generally been adopted by the subsequent scholars [43-46]: (1) Similarity confusion: consumers may misevaluate products or services because of physical similarities. Loken et al. [47] stated that the occurrence of consumer confusion increases when products share a high physical similarity; (2) Overload confusion: consumers may receive excessive information from the environment that prevents them from having sufficient time to understand and process product information; (3) Ambiguity confusion: due to a lack of understanding, consumers may be forced to reevaluate or amend their pre-existing beliefs or assumptions of a product or shopping environment.

\section{Methodology}

\subsection{Hypotheses Development}

This study examined three variables consisting of FRLs and consumer confusions as independent variables, and green consumption intention as dependent variable. Related to the objectives of this study, we develop three hypotheses based on the past studies. The first topic is the relationship of different FRLs towards consumer confusion. A previous study stated that consumers with different lifestyles experience different levels of consumer confusion [48]. FRLs reflect food product usage patterns that may vary from person to person based on the user experience which causes different levels confusion accordingly. This study has the following hypotheses:

Hypothesis 1 (H1). Consumers' experiences (FRLs) significantly influence the consumer confusions.

Hypothesis 1a (H1a). Different consumers' FRLs significantly influence the similarity confusion.

Hypothesis $\mathbf{1 b}$ (H1b). Different consumers' FRLs significantly influence the overload confusion.

Hypothesis 1c (H1c). Different consumers' FRLs significantly influence the ambiguity confusion.

The second topic is the relationship between FRLs and green purchase intention regarding organic infant milk powder. A study conducted by Fang and Lee [49] found that food-related consumer lifestyles significantly influence the consumers intention on 
green consumption. Using this approach, adventurous consumers demonstrated the highest degree of preference towards organic and healthy food, whereas uninvolved and astute consumers did not have interest in these products. Therefore, adventurous food consumers may have higher green consumption intentions, and uninvolved and astute consumers demonstrate the opposite behavior. This indicates that different consumer types exhibit different levels of green consumption intentions. Hence, we proposed Hypothesis 2 as follows:

Hypothesis 2 (H2). Different types of consumer lifestyles related food (FRLs) significantly correlate with green consumption intentions.

The third topic is the relationship between consumer confusion and green purchase intention regarding organic infant milk powder. According to Foxman et al. [50], consumers may experience satisfaction from a purchased product without realizing that it is a counterfeit. Although the infant formulas are counterfeit which mean that the products may be inorganic, consumers may misperceive the products or brands to be organic and feel satisfied. It can further increase the consumer's green consumption intentions. It is also supported by Foxman et al. study that mentioned that consumer confusion does not reduce consumer consumption, but rather increased or strengthened it. The study conducted by Carrete et al. [51] also indicated that consumer confusion influences green behavior. Therefore, this study proposed the following hypotheses:

Hypothesis 3 (H3). Consumer confusion significantly positively correlates with green consumption intention.

Hypothesis 3a (H3a). Similarity confusion significantly positively correlates with green consumption intention.

Hypothesis $\mathbf{3 b} \mathbf{( H 3 b ) . ~ O v e r l o a d ~ c o n f u s i o n ~ s i g n i f i c a n t l y ~ p o s i t i v e l y ~ c o r r e l a t e s ~ w i t h ~ g r e e n ~ c o n s u m p - ~}$ tion intention.

Hypothesis 3c (H3c). Ambiguity confusion significantly positively correlates with green consumption intention.

\subsection{Participants}

The infant milk distribution channels in Taiwan provide marketing channels that are both traditional and physical to promote and sell their products. However, online marketing channels are more varied than physical channels in term of availability of marketing consultants in order to respond to consumers problem including consumer confusion. In this research, we surveyed consumers who join the online marketing channel as the representative of Taiwanese parents because these forums provide more consultation cannels of certain brands, and the members of this forum are parents who have concerns regarding infant milk products problems e.g., product confusion as the focus of this study. As this study only explored the purchase intention on organic infant formula, consumers were not required to make an actual purchase. The targeted respondents were consumers who were more likely to have children or will have children in the near future. Hence, the respondents were parents who have children or couples who do not have children but have an intention to purchase organic infant milk formula.

\subsection{Sampling and Data Collection}

The number of members of the parenting online forum is around 10,000, hence, the number of the distributed questionnaires is in accordance with the forum's population. To determine the number of samples, this study employed probabilistic sampling method, which means that the forum's members have the same chance to respond to the online 
survey. The number of samples were determined to reach the minimum sample for $95 \%$ level of confidence with the margin of error $5 \%$, and also to reach the minimum sample requirement for explanatory factor analysis [52] which is a minimum of 300 samples. While the number of samples for the population about 10,000 members for $95 \%$ level of confidence and margin of error $5 \%$ is 387 samples. Therefore, in this study, we distributed 409 questionnaires online to prevent sample size shortage, and 381 of them were considered as valid data that were used for analysis. The data collection was conducted from 5 January 2019 to 3 February 2019.

\subsection{Data Analysis}

The data consisted of information related to FRLs, consumers' confusion, and green consumption intention regarding organic infant milk formulas that were measured by 5 point Likert scale. After collecting the data, the first step of data analysis was to determine the groups of consumers' FRLs on sustainable behavior. This study used exploratory factor analysis (EFA) to determine the FRL segmentation and conducted cluster analysis to differentiate the consumers using the Brunsø and Grunert's FRL model [9]. The method of clustering used K-Means that treats the data based on the distance from each other. Each cluster is characterized by its center point.

The relationship between FRLs and consumer confusion were examined using oneway analysis of variance (One-way ANOVA). In relation to Hypothesis 1, consumer confusion consists of similarity confusion, overload confusion and ambiguity confusion. Likewise, the correlation of different lifestyle types of consumers (FRLs) on purchase intention (Hypothesis 2) was also analyzed using one-way ANOVA, and we provided the descriptive analysis to describe the different mean scores. Furthermore, to evaluate the Hypothesis 3 , we used Pearson's correlation to understand the correlation of consumer confusion and green consumption intention.

\section{Results}

\subsection{Characteristics of the Respondents}

Table 1 displays the sample description. Most of the participants were women, aged between 23 and 29 years. Based on their educational level, the respondents were mostly college or vocational college (bachelor's degree) graduates. Relating to the nursing infant experience, most of the respondents did not have experience in nursing infants, which is a possibility that they do not have children yet. Most of the respondents had experience in purchasing infant organic foods.

Table 1. Demographic and frequency distribution.

\begin{tabular}{|c|c|c|c|}
\hline Variable & Respondent & Participants & Percentage \\
\hline \multirow[b]{2}{*}{ Gender } & Male & 109 & 28.6 \\
\hline & Female & 272 & 71.4 \\
\hline \multirow{5}{*}{ Age } & $23-29$ & 192 & 50.4 \\
\hline & $30-39$ & 150 & 39.4 \\
\hline & $40-49$ & 20 & 5.2 \\
\hline & $50-59$ & 14 & 3.7 \\
\hline & 60 and above & 5 & 1.3 \\
\hline \multirow{4}{*}{ Education level } & Middle school or lower & 3 & 0.8 \\
\hline & High school or vocational high school & 19 & 5.0 \\
\hline & College or vocational college & 239 & 62.7 \\
\hline & Graduate school and above & 120 & 31.5 \\
\hline \multirow{2}{*}{ Have experience in nursing infants } & Yes & 170 & 44.6 \\
\hline & No & 211 & 55.4 \\
\hline \multirow{2}{*}{$\begin{array}{l}\text { Have experience in purchasing organic milk } \\
\text { formulas }\end{array}$} & Yes & 343 & 90.0 \\
\hline & No & 38 & 10.0 \\
\hline
\end{tabular}




\subsection{Empirical Analysis}

\subsubsection{Exploratory Factor Analysis (EFA) of FRLs}

This study conducted EFA on FRLs to figure out the FRL segmentation. Principal component analysis was employed to extract common factors. Subsequently, this study conducted a varimax rotation to acquire six factors. The result is displayed in Table 2.

Table 2. Exploratory Factor Analysis (EFA) results of FRLs.

\begin{tabular}{|c|c|c|}
\hline Factors & Factor Loading & Factor Loading \\
\hline \multirow{5}{*}{ Cooking attitude } & You enjoy trying new recipes. & 0.662 \\
\hline & You enjoy cooking. & 0.621 \\
\hline & Your family members participate in the cooking process (through any & 0.631 \\
\hline & means). & 0.640 \\
\hline & You always plan meals beforehand (regardless of cooking or eating out). & 0.669 \\
\hline \multirow{4}{*}{ Valuing food quality and planning } & You value food nutrition over taste. & 0.651 \\
\hline & You do not mind paying more for organic products. & 0.657 \\
\hline & You prefer more natural products. & 0.661 \\
\hline & You make shopping lists before shopping. & 0.673 \\
\hline \multirow[t]{2}{*}{ Valuing food information } & $\begin{array}{l}\text { Product information is crucial for you; you want to know about the } \\
\text { ingredients in food products. }\end{array}$ & 0.663 \\
\hline & You select and purchase food according to food labels. & 0.637 \\
\hline \multirow{3}{*}{ Stereotypes and biased } & You believe that cooking is a woman's task. & 0.669 \\
\hline & You feel that purchasing food is a boring task. & 0.731 \\
\hline & You often substitute meals with snacks. & 0.689 \\
\hline \multirow{2}{*}{ Price-oriented } & You always check the price when making purchases. & 0.654 \\
\hline & The cost-performance value of products is critical for you. & 0.672 \\
\hline \multirow{2}{*}{ Selection motivation } & Familiar foods provide you with a sense of security. & 0.675 \\
\hline & When the food you prepared is praised, your self-esteem is strengthened. & 0.686 \\
\hline
\end{tabular}

\subsubsection{Cluster Analysis}

Cluster analysis with K-Means method was employed to find the clusters of customer types according to their FRL. The study determined three points as center points to form the clusters and calculated the distance of each FRL item segment to the center point. The three clusters were determined to seek FRL figure as the worst, middle, and the best lifestyle toward green consumption. The final cluster center is presented in Table 3.

Table 3. FRL cluster analysis with center points.

\begin{tabular}{cccc}
\hline & \multicolumn{3}{c}{ Clusters } \\
\cline { 2 - 4 } & $\mathbf{1}$ & $\mathbf{2}$ & $\mathbf{3}$ \\
\hline Cooking attitude (S1) & -0.609 & 0.203 & 0.389 \\
\hline Values food quality and planning (S2) & -0.0521 & 0.672 & -0.761 \\
\hline Values food information (S3) & -0.362 & 0.023 & 0.349 \\
\hline Stereotypes and biased (S4) & 0.719 & -0.595 & -0.027 \\
\hline Price-oriented (S5) & -0.360 & -0.234 & 0.660 \\
\hline Selection motivation (S6) & 0.257 & -0.152 & -0.083 \\
\hline
\end{tabular}

The result in Table 3 shows the types of customers in each cluster based on their FRLs. The study named the clusters based on the main point of each FRL segment. For example, for Cluster 1, this group has a positive value on stereotypes and bias regarding infant formula products and selection of foods, but the consumers in this cluster have a negative value on cooking attitude, food planning, information, and price orientation. Hence, we 
named them as the consumers who are unfamiliar with food products, and the number of the cases in this research were 122 of 381 respondents. The same process was employed to Cluster 2, and 3, and the explanation for each cluster is as follow:

Cluster 1: Consumers who are unfamiliar with food quality (122)

These consumers hold stereotypical and biased viewpoints toward food products, and they are also not completely uninterested in food quality. This study labeled these consumers as who are unfamiliar with food products and food processing that effect the food quality. Related to organic milk powder, these consumers do not give special attention to this product.

Cluster 2: Consumers who value food quality (142)

The consumers in this cluster enjoy cooking, and they value food information. As these consumers value food quality over the prices, this study labeled these consumers as consumers who value food quality. They also devote themselves in cooking, focus on food quality, and they are attentive to read the information provided in food labels. These people give attention to nutrition contents and have a willingness to pay more for green products including infant milk powder because they care about the impact of food on their health and the environment.

Cluster 3: Consumers who value food practicality (117)

Consumers in this cluster value the food price over quality. These consumers are also devoted to cooking and give attention to food quality information. Therefore, this study labeled these consumers as consumers who value food practicality.

\subsubsection{Reliability Test for Consumer Confusion}

A reliability test was conducted to evaluate the questions of each variable, and the results are presented in Table 4 for consumer confusion and Table 5 for green consumption intention. The Cronbach's alpha of each variable is greater than 0.70 , which indicates that the reliability of the data is good, hence the further analysis can be conducted.

Table 4. Reliability test for consumers' confusion.

\begin{tabular}{|c|c|c|c|}
\hline Consumer Confusion Types & & Items & Cronbach's Alpha \\
\hline \multirow{3}{*}{$\begin{array}{l}\text { Similarity } \\
\text { Confusion }\end{array}$} & 1 & $\begin{array}{l}\text { Since many organic infant formulas are very similar, it will be difficult } \\
\text { for you to find the new products. }\end{array}$ & 0.836 \\
\hline & 2 & $\begin{array}{l}\text { Some organic infant formulas look very similar and you are not sure if } \\
\text { they are from the same manufacturers. }\end{array}$ & 0.828 \\
\hline & 3 & $\begin{array}{l}\text { Sometimes you want to buy a product that you see in an advertisement, } \\
\text { but you cannot easily find it from many similar products. }\end{array}$ & 0.839 \\
\hline \multirow{3}{*}{ Overload Confusion } & 4 & $\begin{array}{l}\text { You are often not sure which organic infant milk formula meets } \\
\text { your needs }\end{array}$ & 0.856 \\
\hline & 5 & You are confused about too many organic infant formula brands & 0.805 \\
\hline & 6 & $\begin{array}{l}\text { Since there are so many ways to buy organic infant formula, it is often } \\
\text { difficult for you to decide where to buy }\end{array}$ & 0.849 \\
\hline \multirow{4}{*}{ Ambiguity confusion } & 7 & $\begin{array}{l}\text { Organic infant milk formula usually has so many different ingredients, } \\
\text { making it difficult for you to compare the different products }\end{array}$ & 0.823 \\
\hline & 8 & Product features are important for you, and you often feel uncertain. & 0.831 \\
\hline & 9 & $\begin{array}{l}\text { You need the help of a salesperson to understand the differences } \\
\text { between different formulas. }\end{array}$ & 0.828 \\
\hline & & Overall & 0.849 \\
\hline
\end{tabular}


Table 5. Reliability test for consumer confusion.

\begin{tabular}{clc}
\hline No. & \multicolumn{1}{c}{ Items } & Cronbach's Alpha \\
\hline 1 & You will choose organic infant formulas that help reduce pollution & 0.766 \\
2 & You will not buy organic infant formulas that may harm the environment & 0.727 \\
3 & You will give preference to products packaged in recyclable containers & 0.740 \\
4 & $\begin{array}{l}\text { You will convince your family or friends to not buy organic infant formulas that are harmful to } \\
\text { the environment }\end{array}$ & 0.701 \\
5 & You will choose organic infant milk powder products with reduced packaging & 0.754 \\
6 & You will try to buy organic milk formula & 0.732 \\
7 & You will give priority to the infant formulas with the lowest price & 0.852 \\
8 & If there are both (general formula milk powder) and (organic formula milk powder) to be & 0.740 \\
\hline & selected, you will give priority to organic formula milk powder. & Overall \\
\hline
\end{tabular}

\subsubsection{Hypothesis Testing}

\section{Correlation of Different Consumers FRLs with Consumer Confusion}

To examine consumer lifestyles (FRLs) with consumer confusion, we first observed the homogeneity of variance using Levene's test. If the $p$-value equals or greater than 0.05 , the homogeneity of variance test is not violated. The further analysis is the ANOVA test to examine the significance and the Scheffe test to compare the mean differences. However, if the homogeneity of variance is violated ( $p$-value is less than 0.05 ), the Brown-Forsythe test and Welch's $t$-test is employed to test whether the two populations have equal means. If the result is significant, the Games-Howell test is used for post-hoc multiple comparisons. The homogeneity test on different consumers' experiences and different levels of consumer confusion is presented in Table 6.

Table 6. Homogeneity of variance of similarity, overload, and ambiguity confusion.

\begin{tabular}{ccccc}
\hline & Levene Stat & Numerator Df & Denominator Df & $p$-Value \\
\hline Similarity confusion & 5.116 & 2 & 378 & 0.006 \\
Overload confusion & 4.735 & 2 & 378 & 0.009 \\
Ambiguity confusion & 7.664 & 2 & 378 & 0.001 \\
\hline
\end{tabular}

The result indicates that the $p$-value from the homogeneity test is less than 0.05 , thus, the homogeneity of variance assumption is rejected. Therefore, the Brown-Forsythe and Welch's $t$-test as presented in Table 7 were employed to compute whether the two populations had equal means.

Table 7. Mean test of FRLs and confusion types.

\begin{tabular}{cccccc}
\hline & & Stat & Nominator Df & Denominator Df & Sig. \\
\hline Similarity & Welch & 0.507 & 2 & 244.276 & 0.603 \\
confusion & Brown-Forsythe & 0.572 & 2 & 345.473 & 0.565 \\
\hline Overload & Welch & 0.453 & 2 & 246.536 & 0.636 \\
confusion & Brown-Forsythe & 0.405 & 2 & 360.591 & 0.667 \\
\hline Ambiguity & Welch & 0.579 & 2 & 244.366 & 0.561 \\
confusion & Brown-Forsythe & 0.580 & 2 & 345.750 & 0.560 \\
\hline
\end{tabular}

The result reveals that the $p$-value is greater than 0.05 which mean that the different types of FRLs do not significantly correlate with confusion (Hypothesis 1 is rejected). This result differs from that Drummond and Rule [48] study which found that different types of consumers significantly influence consumer confusion. Different types of FRLs reflect the different behaviors toward food selection including way of shopping, cooking method, 
quality valuation, and purchase motivation [9]. This finding indicates that the different levels of awareness on food quality do not correlate with confusion on organic infant milk formulas.

Correlation of Different Type of Consumers' FRLs with Green Consumption Intentions

Similar to the process to test Hypothesis 1, homogeneity test was carried out to evaluate the homogeneity of paired FRLs and green consumption, and the result is presented in Table 8 . The result shows that $p$-value is 0.081 which is greater than 0.05 , hence, the ANOVA test was further used to examine the significance, and the result presented in Table 9. The result shows the significant difference among the different types of consumers' FRLs with green consumption intention (Hypothesis 2 is accepted).

Table 8. Homogeneity of variance for green consumption intention.

\begin{tabular}{cccc}
\hline Levene Stat & Nominator Df & Denominator Df & Sig. \\
\hline 2.533 & 2 & 378 & 0.081 \\
\hline
\end{tabular}

Table 9. ANOVA test on the different FRLs on the green consumption intention.

\begin{tabular}{cccccc}
\hline & Sum of Squares & Df & Mean Sum of Squares & F & Sig. \\
\hline Between & 5.827 & 2 & 2.913 & 10.735 & $0.000^{*}$ \\
Error & 102.578 & 378 & 0.271 & & \\
Total & 108.405 & 380 & & & \\
\hline Note: ${ }^{*}=$ the correlation is significant at 0.05 level $(p$-value $=0.05$ or less). &
\end{tabular}

Since in this study we evaluate different type of customers based on their FRLs and grouped in clusters, the Scheffe test presented in Table 10 was conducted to reveal the level of green consumers intention of each cluster. The result shows that the Cluster 1 is significantly different from the Cluster 2 , but it is not significantly different from the Cluster 3. The Cluster 2 is significantly different from the Cluster 3.

Table 10. Scheffe test on post-hoc multiple comparisons of the green consumption intention of different types of consumers.

\begin{tabular}{llcc}
\hline \multicolumn{1}{c}{ Clusters (I) } & \multicolumn{1}{c}{ (J) Cluster } & Mean Difference (I-J) & $p$-Value \\
\hline $\begin{array}{l}\text { Cluster 1 } \\
\begin{array}{l}\text { Cluster Consumers who are unfamiliar } \\
\text { with food products }\end{array}\end{array}$ & $\begin{array}{l}\text { Consumers who value food quality (Cluster 2) } \\
\text { Consumers who value food practicality } \\
\text { (Cluster 3) }\end{array}$ & -0.172 & $0.029^{*}$ \\
\hline $\begin{array}{l}\text { Cluster 2 } \\
\text { Consumers who value food quality }\end{array}$ & $\begin{array}{l}\text { Consumers who are unfamiliar with food } \\
\text { products (Cluster 1) } \\
\text { Consumers who value food practicality } \\
\text { (Cluster 3) }\end{array}$ & 0.126 \\
\hline $\begin{array}{l}\text { Cluster 3 } \\
\text { Consumers who value food practicality }\end{array}$ & $\begin{array}{l}\text { products (Cluster 1) } \\
\text { Consumers who value food quality (Cluster 2) }\end{array}$ & 0.172 \\
\hline
\end{tabular}

Note: ${ }^{*}=$ the difference is significant at 0.05 level ( $p$-value $=0.05$ or less).

\section{Correlation between Consumer Confusion and Green Consumption Intentions}

Pearson's correlation to evaluate the correlation of consumer confusion with green consumption intentions is provided in Table 11. All the categories of consumer confusion are significantly correlated with green consumption intention (Hypothesis 3, Hypothesis 3a, Hypothesis $3 b$, and Hypothesis $3 c$ are accepted). The positive value of coefficient correlation denotes the uphill linear relationship, which means that when the confusion increases the intention on green consumption also increases. 
Table 11. Correlation analysis between consumer confusion and green consumption intention.

\begin{tabular}{ccc}
\hline & & Green Consumption Intention \\
\hline \multirow{2}{*}{ Similarity confusion } & Pearson correlation & $0.282^{* *}$ \\
& Sig. (two-tailed) & 0.000 \\
\hline \multirow{2}{*}{ Overload confusion } & Pearson correlation & $0.178^{* *}$ \\
& Sig. (two-tailed) & 0.000 \\
\hline \multirow{2}{*}{ Ambiguity confusion } & Pearson correlation & $0.253^{* *}$ \\
& Sig. (two-tailed) & 0.000 \\
\hline
\end{tabular}

Note: ${ }^{* *}=$ the correlation is very significant at 0.01 or less (two-tailed).

\section{Discussion}

Food safety is an absolute necessity for people especially for infants who have higher vulnerability. The shifting to green consumption intention of Taiwanese parents to provide healthy food to their children is also indicated by the FRLs in this study. Through cluster analysis, the cluster of consumers who valued the food quality (Cluster 2) is the highest among the others with the percentage $37 \%$ followed by the consumers who are unfamiliar with green food products (Cluster 1) with the percentage 32\%, and consumers who value food practicality (Cluster 3$)$ with the percentage $31 \%(C 2>C 1>C 3)$. This result is supported by previous study on organic food in Vietnam conducted by Van and Hui (2019) [28] which mentioned that the percentage of type of people who value highly food quality named as conservative people was also the highest compared to the other clusters (trendsetter and unengaged to organic food). Differing from Radojevic' et al.'s [53] study in Serbia regarding organic food purchase, the consumer cluster which concern in organic food was not the highest in comparison to the others. The consumers mostly buy foods based on its aesthetic value, the ease of recognition of the product label and information, and the healthiness that has not to be organic food. While the organic food consumers were in the second rank among the clusters, followed by the consumers who have less attention to food quality.

In this study, it was also found that different types of consumers' FRLs significantly influence the infant milk formula purchase (Table 9), where Cluster 2 have concerns regarding the quality of food which include nutrition and food safety. They also have concerns with seeking the information of foods that they will purchase. The result in Table 10 also denotes that the consumers in Cluster 2 significantly differ from Cluster 1 and Cluster 3 regarding the organic infant milk purchase. This group has high awareness on sustainable consumption and safety food even though the organic foods are generally more expensive than inorganic food. Similar to this finding, Fang and Lee [49] argued that consumers who are more concerned with the quality of food termed as "adventurous consumers", have higher intentions towards green consumption. This finding is also in line with the previous studies which mentioned that green self-concept [54] and subjective knowledge on environmental issues [55] positively correlate with green purchase intention.

The increasing Taiwanese intentions towards organic products including infant milk powder have encouraged green marketing development by the release of a number of green labels. Unfortunately, for organic infant milk formulas, Taiwanese consumers rely on imported products which can cause confusion with unfamiliar brands and certifications, similar brands, and unclear information. All the tested consumer confusions (similarity, overload, and ambiguity confusions) on organic infant milk powder in Table 7 did not significantly correlate with FRLs. FRLs are a comprehensive eating behavior that include many aspects grouped in five criteria in this study. Hence, the confusion on infant milk brand did not significantly influence the FRLs.

However, related to infant milk purchase, the consumer confusion levels positively correlate with the green consumption intention level which the result is present in Table 11. This result is consistent with Carrete et al. [51] study which found that consumer confusion influences green behavior. However, this finding is contrary to the previous study which 
found that the green confusion negatively influences green purchase intention [56]. Explaining this result, Liu [37] mentioned that consumers' confusion indicates consumers' awareness to distinguish the products and to make decision on purchase (to buy or not). In this study, the items of confusion are related to consumers' agreement regarding various organic infant formulas (huge brands and mostly similar packaging) with a number of marketing tricks that cause consumer confusion. Hence, their opinion reflects their understanding and awareness on greenwashing. Greenwash is defined as the act of misleading consumers on environmental practices by a company in order to gain benefits of a product or a service [57]. Hence, when the awareness of green products increases, the intention to purchase green products also increases. This condition also explains the situation in Taiwan. The intention to organic consumption in Taiwan increases year by year. Even though the Taiwanese consumers were confused by numerous milk products, the organic milk consumption is still increasing because the consumers shift to other organic milk products for example fresh milk that it is believed to be safer, more secure, and less contaminated from in-organic materials, as reported by United Stated Department of Agriculture (USDA) $[58,59]$. The report mentioned that dried milk powder including organic milk powder slightly decreasing about $1.37 \%$ per year by 37 MT in 2012 to be 33 MT in 2020 and the consumption shifted to fresh milk.

Reflecting to the result of the study, the Taiwanese consumer confusion on huge brands and unclear product information of infant milk powder brands should be given importance by the government e.g., through promoting logos or labels for both local and international products to increase the public trust. Even though the Taiwanese consumers have high FRLs on food quality and have high intention to buy organic foods, the government should improve the protection for consumers by managing the distribution of imported products. It is important to achieve the green consumption and sustainable economic development. The information in this study also can be used by suppliers and distributors to develop strategies on to decrease consumer confusion by improving information of products on labels, traceability, avoiding similar brand packaging, and shelf management.

\section{Conclusions}

Green consumption is a shared global concept that is commonly discussed by scholars in the field of consumer behavior. However, numerous aspects in this field have yet to be discussed, including organic infant formulas, a product that is rarely associated with this field. This study mainly explored how consumers with different FRLs exhibit different degrees of confusion and green consumption intentions and analyzed the relationship between consumer confusion and green consumption intention. This study found that people-lifestyle related food decisions can be categorized as people who are unfamiliar with food quality or they do not care about food quality, the people who pay attention to food quality and environment through focusing on green consumption, and the people who care about food quality practicality but they still consider the price of products. People who valued food based on quality have the highest intention to consume green products including the purchase of organic infant milk formulas for their children compared those who are unfamiliar with food quality, and those who valued food quality practicality. A degree of consumer confusion, out of all the different confusion (similarity, overload, and ambiguity confusions), positively correlated with green consumption intention of organic infant formulas.

The result of the study can be used as a source of information on an academic sphere in social studies. This result also can be used by the government to develop consumer trust on imported milk powder, and for suppliers to develop strategies to develop sustainable marketing. However, this study still has limitations; this study still did not analyze comprehensively other social aspects, for example, the FRL clustering based on demographic, and significance of respondents' characteristic toward FRLs and different confusion. Hence, this study can be further completed by other scholars in order to achieve a more complete scientific examination on this topic. 
Author Contributions: Conceptualization, methodology, data collection, analysis, validation, and written by S.-P.Y., T.-C.L., R.O.P.S., M.H. and S.-C.C.; Supervision by S.-C.C. All authors have read and agreed to the published version of the manuscript.

Funding: This research received no external funding.

Institutional Review Board Statement: Ethical review is not applicable, because despite the fact that it was an Organic Infant Milk Formula study, it was an online survey that only requires anonymous respondents' opinion.

Informed Consent Statement: Informed consent was obtained from all the subjects in the study.

Data Availability Statement: The data that support the findings are available on the request from the corresponding author.

Conflicts of Interest: The authors declare no conflict of interest.

\section{References}

1. Yu, N.; Lai, M.S. International development trends for green consumers. Sci. Dev. 2005, 387, $20-25$.

2. Commission of the European Communities. Green Paper on Integrated Product Policy; Commission of the European Communities: Brussels, Belgium, 2001.

3. Shamdasani, P.; Chon-Lin, G.O.; Richmond, D. Exploring green consumers in an oriental culture: Role of personal and marketing mix factors. Adv. Cons. Res. 1993, 20, 488-493.

4. Vapa-Tankosić, J.; Ignjatijević, S.; Kiurski, J.; Milenković, J.; Milojević, I. Analysis of consumers' willingness to pay for organic and local honey in Serbia. Sustainability 2020, 12, 4686.

5. Tomaš-Simin, M.; Glavaš-Trbic, D.; Petrovic, M. Organic production in the Republic of Serbia: Economic aspects. Ekon. Teor. Praksa 2019, 12, 88-101. [CrossRef]

6. Lyu, J.C. A comparative study of crisis communication strategies between Mainland China and Taiwan: The melamine-tainted milk powder crisis in the Chinese context. Public Relat. Rev. 2012, 38, 779-791. [CrossRef]

7. Taiwan Organic Information Portal. Yearly Report of Organic Agricultural Land and Farm in Taiwan. 2020. Available online: https:/ / info.organic.org.tw/5138/ (accessed on 15 January 2021).

8. Schwartz, B. The Tyranny of Choice. Sci. Am. 2004, 290, 70-75. [CrossRef] [PubMed]

9. Brunsø, K.; Grunert, K.G. Cross-Cultural Similarities and Differences in Shopping for Food. J. Bus. Res. 1998, 42, 145-150. [CrossRef]

10. Elkington, J.; Hailes, J. The Green Consumer Guide; Victor Gollancz Ltd.: London, UK, 1989.

11. Ottman, J.A.; Stafford, E.R.; Hartman, C.L. Avoiding green marketing myopia: Ways to improve consumer appeal for environmentally preferable products. Environment 2006, 48, 22-36. [CrossRef]

12. Speth, J.G. The Bridge at the Edge of the World: Capitalism, the Environment, and Crossing from Crisis to Sustainability; Yale University Press: New Haven, CT, USA, 2008.

13. Haws, K.L.; Winterich, K.P.; Naylor, R.W. Seeing the world through GREEN-tinted glasses: Green consumption values and responses to environmentally friendly products. J. Consum. Psychol. 2014, 24, 336-354. [CrossRef]

14. Akenji, L. Consumer scapegoatism and limits to green consumerism. J. Clean. Prod. 2014, 63, 13-23. [CrossRef]

15. Nimse, P.; Vijayan, A.; Kumar, A.; Varadarajan, C. A review of green product databases. Environ. Prog. Sustain. Energy 2007, 26, 131-137. [CrossRef]

16. Chen, T.B.; Chai, L.T. Attitude towards the environment and green products: Consumers' perspective. Manag. Sci. Eng. 2010, 4 , 27-39.

17. Junior, S.S.B.; Da Silva, D.; Gabriel, M.L.D.; de Oliveira Braga, W.R. The effects of environmental concern on purchase of green products in retail. Procedia Soc. Behav. Sci. 2015, 170, 99-108. [CrossRef]

18. Green Workshop. Green Consumption; Publishing House of Minority Nationalities: Beijing, China, 1999.

19. Kemper, J.A.; Hall, C.M.; Ballantine, P.W. Marketing and sustainability: Business as usual or changing worldviews? Sustainability 2019, 11, 780. [CrossRef]

20. Kowalska, M. SME managers' perceptions of sustainable marketing mix in different socioeconomic conditions-a comparative analysis of Sri Lanka and Poland. Sustainability 2020, 12, 10659. [CrossRef]

21. Cooper, T. Slower consumption reflections on product life spans and the "throwaway society". J. Ind. Ecol. 2005, 9, 51-67. [CrossRef]

22. Kumar, V.; Rahman, Z.; Kazmi, A.; Goyal, P. Evolution of sustainability as marketing strategy: Beginning of New Era. Procedia Soc. Behav. Sci. 2012, 37, 482-489. [CrossRef]

23. Pomering, A. Marketing for sustainability: Extending the conceptualization of the marketing mix to drive value for individuals and society at large. Australas. Mark. J. 2017, 25, 157-165. [CrossRef]

24. Lazer, W. Life style concepts and marketing. Towar. Sci. Mark. 1963, 12, 130-139.

25. Plummer, J.T. The concept and application of life style segmentation. J. Mark. 1974, 38, 33-37.

26. Lawson, R.; Todd, S. Consumer lifestyles: A social stratification perspective. Mark. Theory 2002, 2, 295-307. [CrossRef] 
27. Bernués, A.; Ripoll, G.; Panea, B. Consumer segmentation based on convenience orientation and attitudes towards quality attributes of lamb meat. Food Qual. Prefer. 2012, 26, 211-220. [CrossRef]

28. Van Huy, L.; Chi, M.T.T.; Lobo, A.; Nguyen, N.; Long, P.H. Effective segmentation of organic food consumers in Vietnam using food-related lifestyles. Sustainability 2019, 11, 1237. [CrossRef]

29. Thøgersen, J. Housing-related lifestyle and energy saving: A multi-level approach. Energy Policy 2017, 102, 73-87. [CrossRef]

30. Situmorang, R.O.; Liang, T.-C.; Chang, S.-C. The difference of knowledge and behavior of college students on plastic waste problems. Sustainability 2020, 12, 7851. [CrossRef]

31. Todd, S.; Lawson, R.; Faris, F. A lifestyle analysis of New Zealand customers. Asia Pac. J. Mark. Logist. 1998, 10, 30-47. [CrossRef]

32. Nie, C.; Zepeda, L. Lifestyle segmentation of US food shoppers to examine organic and local food consumption. Appetite 2011, 57, 28-37. [CrossRef]

33. Reynolds, F.D.; Darden, W.R.; Martin, W.S. Developing an image of store-loyal customer-life-style analysis to probe a neglected market. J. Retail. 1974, 50, 73-84.

34. Brunsø, K.; Scholderer, J.; Grunert, K.G. Closing the gap between values and behavior-a means-end theory of lifestyle. J. Bus. Res. 2004, 57, 665-670. [CrossRef]

35. O'Sullivan, C.; Scholderer, J.; Cowan, C. Measurement equivalence of the food related lifestyle instrument (FRL) in Ireland and Great Britain. Food Qual. Prefer. 2005, 16, 1-12. [CrossRef]

36. Lu, W.X. Discussion on Patent Improvement, Patent Likelihood of Confusion, and Fair Use of Copyright; Rui-Xing Enterprise Co.: Taipei, Taiwan, 2006.

37. Liu, K.C. Likelihood of Confusion-Trademark Act; Wu-Nan Book Inc.: Taipei, Taiwan, 1997.

38. Shenkar, O. Copycats: How smart companies use imitation to gain a strategic edge. Strat. Dir. 2010, 26, 3-5. [CrossRef]

39. Foxman, E.R.; Berger, P.W.; Cote, J.A. Consumer brand confusion: A conceptual framework. Psychol. Mark. 1992, 9, $123-141$. [CrossRef]

40. Walsh, G.; Mitchell, V.W. The Effect of consumer confusion proneness on word of mouth, trust, and customer satisfaction. Eur. J. Mark. 2010, 44, 838-859. [CrossRef]

41. Turnbull, P.W.; Leek, S.; Ying, G. Customer confusion: The mobile phone market. J. Mark. Manag. 2000, 16, 143-163. [CrossRef]

42. Mitchell, V.W.; Walsh, G.; Yamin, M. Towards a conceptual model of consumer confusion. Adv. Cons. Res. 2005, 32, 143-150.

43. Sachse, M.; Drengner, J.; Jahn, S. Negative effects of event sponsoring and ambushing: The case of consumer confusion. Adv. Cons. Res. 2010, 37, 546-547.

44. Matzler, K.; Stieger, D.; Füller, J. Consumer confusion in internet-based mass customization: Testing a network of ante-cedents and consequences. J. Cons. Pol. 2011, 34, 231-247. [CrossRef]

45. Leek, S.; Szmigin, I.; Baker, E. Consumer confusion and front of pack (FoP) nutritional labels. J. Cust. Behav. 2015, 14, 49-61. [CrossRef]

46. Spiteri Cornish, L.; Moraes, C. The impact of consumer confusion on nutrition literacy and subsequent dietary behavior. Psychol. Mark. 2015, 32, 558-574. [CrossRef]

47. Loken, B.; Ross, I.; Hinkle, R.L. Consumer "confusion" of origin and brand similarity perceptions. J. Publ. Policy Mark. 1986, 5, 195-211. [CrossRef]

48. Drummond, G.; Rule, G. Consumer confusion in the UK wine industry. J. Wine Res. 2005, 16, 55-64. [CrossRef]

49. Fang, C.-H.; Lee, H.-J. Food-related lifestyle segments in Taiwan: Application of the food-related lifestyle instrument. Am. J. Appl. Sci. 2009, 6, 2036-2042. [CrossRef]

50. Foxman, E.R.; Muehling, D.D.; Berger, P.W. An Investigation of factors contributing to consumer brand confusion. J. Consum. Aff. 1990, 24, 170-189. [CrossRef]

51. Carrete, L.; Castaño, R.; Felix, R.; Centeno, E.; González, E. Green consumer behavior in an emerging economy: Confusion, credibility, and compatibility. J. Consum. Mark. 2012, 29, 470-481. [CrossRef]

52. Comrey, A.L.; Lee, H.B. A First Course in Factor Analysis; Lawrence Erlbaum Associates: Mahwah, NJ, USA, 1992.

53. Radojevic, V.; Tomaš Simin, M.; Glavaš Trbic, D.; Milic, D. A Profile of organic food consumers-Serbia case-study. Sustainability 2021, 13, 131. [CrossRef]

54. Sharma, N.; Saha, R.; Sreedharan, V.R.; Paul, J. Relating the role of green self-concepts and identity on green purchasing behaviour: An empirical analysis. Bus. Strat. Environ. 2020, 29, 3203-3219. [CrossRef]

55. Liang, T.-C.; Situmorang, R.O.; Liao, M.-C.; Chang, S.-C. The relationship of perceived consumer effectiveness, subjective knowledge, and purchase intention on carbon label products-a case study of carbon-labeled packaged tea products in Taiwan. Sustainability 2020, 12, 7892. [CrossRef]

56. Tarabieh, S. The impact of greenwash practices over green purchase intention: The mediating effects of green confusion, Green perceived risk, and green trust. Manag. Sci. Lett. 2020, 11, 451-464. [CrossRef]

57. Parguel, B.; Benoît-Moreau, F.; Larceneux, F. How sustainability ratings might deter 'greenwashing': A closer look at ethical corporate communication. J. Bus. Ethics 2011, 102, 15. [CrossRef]

58. USDA. Taiwan Dairy and Product Annual 2012; United Stated Department of Agriculture (USDA) Foreign Agriculture: Washington, DC, USA, 2012.

59. USDA. Taiwan Dairy and Product Annual 2020; United Stated Department of Agriculture (USDA) Foreign Agriculture: Washington, DC, USA, 2020. 